\title{
The Linked CENTURY Study: linking three decades of clinical and public health data to examine disparities in childhood obesity
}

Summer Sherburne Hawkins ${ }^{1 *} \mathbb{D}$, Matthew W. Gillman², Sheryl L. Rifas-Shiman², Ken P. Kleinman², Megan Mariotti ${ }^{3}$ and Elsie M. Taveras ${ }^{4,5}$

\begin{abstract}
Background: Despite the need to identify the causes of disparities in childhood obesity, the existing epidemiologic studies of early life risk factors have several limitations. We report on the construction of the Linked CENTURY database, incorporating CENTURY (Collecting Electronic Nutrition Trajectory Data Using Records of Youth) Study data with birth certificates; and discuss the potential implications of combining clinical and public health data sources in examining the etiology of disparities in childhood obesity.

Methods: We linked the existing CENTURY Study, a database of 269,959 singleton children from birth to age 18 years with measured heights and weights, with each child's Massachusetts birth certificate, which captures information on their mothers' pregnancy history and detailed socio-demographic information of both mothers and fathers.

Results: Overall, $74.2 \%$ were matched, resulting in 200,343 children in the Linked CENTURY Study with 1,580,597 well child visits. Among this cohort, $94.0 \%(188,334)$ of children have some father information available on the birth certificate and $60.9 \%(121,917)$ of children have at least one other sibling in the dataset.

Using maternal race/ethnicity from the birth certificate as an indicator of children's race/ethnicity, $75.7 \%$ of children were white, $11.6 \%$ black, $4.6 \%$ Hispanic, and $5.7 \%$ Asian. Based on socio-demographic information from the birth certificate, $20.0 \%$ of mothers were non-US born, $5.9 \%$ smoked during pregnancy, $76.3 \%$ initiated breastfeeding, and $11.0 \%$ of mothers had their delivery paid for by public health insurance. Using clinical data from the CENTURY Study, $22.7 \%$ of children had a weight-for-length $\geq 95^{\text {th }}$ percentile between 1 and 24 months and $12.0 \%$ of children had a body mass index $\geq 95^{\text {th }}$ percentile at ages 5 and 17 years.

Conclusions: By linking routinely-collected data sources, it is possible to address research questions that could not be answered with either source alone. Linkage between a clinical database and each child's birth certificate has created a unique dataset with nearly complete racial/ethnic and socio-demographic information from both parents, which has the potential to examine the etiology of racial/ethnic and socioeconomic disparities in childhood obesity.
\end{abstract}

Keywords: Birth certificates, Electronic health records, Health status disparities, Medical record linkage, Pediatric obesity

\footnotetext{
*Correspondence: summer.hawkins@bc.edu

${ }^{1}$ Boston College, School of Social Work, McGuinn Hall, 140 Commonwealth

Avenue, Chestnut Hill, MA, USA

Full list of author information is available at the end of the article
} 


\section{Background}

Despite recent evidence that childhood obesity in the US may have plateaued or even decreased [1,2], progress has not been universal. From 2008 through 2011, the prevalence of obesity in low-income children age 2-4 years decreased in 19 of 43 states and territories, but remained high overall with a prevalence of $14 \%$ [2]. According to nationally-representative data, obesity rates have also decreased among 2- to 5-year-olds, resulting in a prevalence of $8 \%$ [1]. However, racial/ethnic disparities persist. In 2011-2012, $4 \%$ of preschool-age white children were obese, compared to $11 \%$ of black children, and $17 \%$ of Hispanic children [1]. In contrast, obesity rates among older children have remained stable over the past decade at $18-21 \%$ and ethnic minority children continue to be at higher risk [1]. In 2011-2012, $13 \%$ of 6-11-year-old white children were obese, compared to $24 \%$ of black children, and $26 \%$ of Hispanic children [1]. Examining the causes of racial/ethnic and socioeconomic disparities in childhood obesity could help inform preventive interventions among those populations at highest risk.

Life course epidemiology proposes that factors during peri- and post-natal periods may influence the development of obesity from early life through adulthood [3, 4]. Observational studies have shown that maternal smoking during pregnancy [5-7], excessive gestational weight gain [8-10], gestational diabetes mellitus (GDM) [11], and accelerated infant weight gain $[6,12,13]$ are associated with higher risk for childhood obesity. Some, but not all studies, also suggest that breastfeeding is protective [14-17]. More recently, cesarean delivery [18, 19] and antibiotic exposure in the first year of life [20,21] have been associated with childhood obesity. At a more macro-level, aspects of the built and socioeconomic environment, such as access to food, opportunities for physical activity, and neighborhood deprivation [22-28], have been associated with childhood obesity and may explain racial/ethnic differences in obesity [29-31].

However, the existing epidemiologic studies of early life risk factors have several limitations. Foremost, the majority of research has been from observational studies of singletons, which are subject to confounding by genetic and shared environmental and familial factors. Given that randomized trials are often neither ethical nor feasible, alternative study methodologies, such as sibling pair designs [32], can reduce confounding and thus provide more valid inferences. Differences in outcomes between siblings can be compared when they have different exposures in utero or after birth, such as nicotine exposure if their mother smoked during one pregnancy but not the other. Since this methodology allows for partial control of the pre- and post-natal environment as well as shared genes [32, 33], it produces a less confounded estimate. If confounding is present, sibling-pair effect sizes would be smaller than those in an overall (between-family) analysis of the same data [33]. However, to date, there have been only a few sibling pair studies of any peri- or post-natal risk factors for childhood obesity [34-44]. Thus, whether many of the known risk factors are causally related to obesity remains unresolved.

In the US there are limited data sources that have information on peri- and post-natal risk factors, measured height and weight across childhood, racial/ethnic and socioeconomic diversity, and geocodes. Birth cohort studies $[45,46]$ have been invaluable resources because they collect detailed information on a range of exposure and outcome measures, but they often include a limited number of subjects and power to test interactions between race/ethnicity and measures of social class. Cohort studies also generally enroll only a single child from each family and, consequently, have limited sibling pairs.

Data linkage is a cost-effective approach to adding further value to routinely-collected data. State laws require that birth certificates be completed for all births and detailed information is collected on peri- and post-natal risk factors; however, health outcomes after discharge are not available. In contrast, clinical databases created from electronic health records contain child health outcomes, but information is often missing on socio-demographics and peri- or post-natal information. Linking these two sources of data can marry the advantages of each to overcome some of the noted limitations of previous study designs and help address the early origins of disparities in childhood obesity.

This paper first reports on the construction of the Linked CENTURY Study through data linkage between the CENTURY (Collecting Electronic Nutrition Trajectory Data Using e-Records of Youth) Study, a clinical database with measured height and weight data [47-49], with each child's Massachusetts birth certificate; and second, discusses the potential clinical, epidemiologic, and public health implications of the Linked CENTURY Study in examining the etiology of disparities in childhood obesity.

\section{Methods \\ CENTURY study}

With funding from the Centers for Disease Control and Prevention in 1996, 2001, and 2008, we created the CENTURY Study, a database of children ages 0 to $<18.0$ years who were seen for a well child visit at any of the 14 health centers of Harvard Vanguard Medical Associates (HVMA) and other smaller health centers in eastern Massachusetts (currently Atrius Health) from 1980 through 2008. Originally a staff model health maintenance organization, HVMA evolved into a group practice in 1998. Its patients are predominantly employed and insured; children with 
Medicaid insurance were accepted from 1987 onwards. Since HVMA's inception in 1969, it has used a completely electronic health record system for all medical encounters. To generate the CENTURY database, we obtained demographic and growth data from all well child visits from 1980 through 2008, for those children born from 1969 onwards. The definition of a well child visit was the use of an appropriate utilization code, the combination of measurement of weight and length or height, or administration of a routine immunization. The total sample size of the database is 306,147 children from birth to age 18 years with 2,110,014 well child visits from 1980 through 2008 . Each child in the database was linked to his/her mother using insurance information and siblings were identified through a common family identifier. It is, therefore, possible that siblings may or may not be biological.

\section{Measures from well child visits}

Birth weight Birth weight was extracted using both medical chart abstraction and text-search algorithms. Text-search algorithms use computational models that map clinical text to extract contextual use of words and phrases. Similar models have been used in electronic health records to identify adverse events of clinical care [50] and validate clinical diagnoses [51]. Birth weight is available in the CENTURY database for approximately $32 \%$ of children.

Weights and lengths Medical assistants measured length or height and weight according to the written protocol of the HVMA health centers. Weight was measured to the nearest $0.25 \mathrm{lb}$ on a pediatric scale. Length in children $<24$ months was measured recumbent. For children older than 36 months, height was generally measured standing. Medical assistants used a paper-andpencil technique for children $<24$ months rather than the recommended recumbent measuring board. In a measurement validation study conducted at one of the participating health centers, we found that this paperand-pencil method systematically overestimated children's length compared with the standard method. Thus, in all analyses of the CENTURY data, we correct recumbent length for children younger than 24 months using a regression correction factor from the validation study to adjust for this systematic overestimation [52].

We used measured height and weight to calculate ageand sex-specific weight-for-length (WFL) and body mass index (BMI) percentiles based on the Centers for Disease Control and Prevention (CDC) growth charts from 2000. The CDC defines obesity in children age 2-19 years as a BMI at or above the $95^{\text {th }}$ percentile for age and sex, with overweight between the $85^{\text {th }}$ and $95^{\text {th }}$ percentiles [53]. We used age- and sex-specific weight-for- length percentiles based on the $2000 \mathrm{CDC}$ growth chart for children $<24.0$ months [53].

Blood pressure Medical assistants routinely take children's blood pressure at well visits starting at age 3 according to the written protocol of the HVMA health centers. The protocol, which is based on recommendations from the American Heart Association [54], instructs patients to sit for five minutes before measuring blood pressure. It includes using a cuff that fits appropriately. Blood pressure is measured using automated or manual instruments, depending on what is available at each site.

We used clinical blood pressure readings to calculate age-, sex- and height-specific systolic blood pressure and diastolic blood pressure percentiles according to National Health Lung and Blood Institute guidelines [55].

Socio-demographic information From the clinical record, we obtained the child's gestational age, sex, age at the time of the visit, and type of medical insurance. Parental or clinician report of child's race/ethnicity was recorded using the categories white, black, Hispanic, American Indian/Alaska Native, Asian, and other.

Due to the challenge of linking children from multiple birth pregnancies (i.e., twins, triplets) with their birth certificate, we retained 269,959 singleton children. Sample characteristics of the singleton children from the original CENTURY Study are shown in Table 1. All of the children had weight and height or length recorded at least once. However, information is missing on child's race/ethnicity for $36 \%$ of participants and medical insurance status for $66 \%$ of participants.

\section{Massachusetts Department of Public Health (MDPH) birth certificate data}

Information on all live births in Massachusetts is stored in the Registry of Vital Records and Statistics at MDPH. The Massachusetts Standard Certificate of Live Birth, referred to as the 'birth certificate', consists of a Parent Worksheet and a Hospital Worksheet. The parent(s) completes the Parent Worksheet, which contains legal and socio-demographic information on the child's mother and father. While the birth certificate does not confirm that the father is biological, it states that the information provided is about the child's father regardless of whether the father will appear on the child's legal birth record. A designated hospital representative (e.g., doctor, nurse, or hospital birth registrar) completes the Hospital Worksheet, which contains information on prenatal care, labor and delivery, neonatal conditions and procedures, and discharge. 
Table 1 Sample socio-demographic characteristics, maternal health behaviors, and childhood obesity and blood pressure outcomes of the singleton children from the existing CENTURY study and Linked CENTURY study (linked with each child's Massachusetts birth certificate), 1980-2008

\begin{tabular}{|c|c|c|c|c|}
\hline \multirow[b]{2}{*}{ Characteristics } & \multicolumn{2}{|c|}{ CENTURY Study } & \multicolumn{2}{|c|}{$\begin{array}{l}\text { Linked CENTURY } \\
\text { Study }\end{array}$} \\
\hline & Total $N$ & $\%$ & Total N & $\%$ \\
\hline Any data at age $\leq 18$ years & 269959 & & 200343 & \\
\hline Any data at age $<2$ years & 121389 & $45.0 \%$ & 104584 & $52.2 \%$ \\
\hline Any data at age 5 years & 72195 & $26.7 \%$ & 57547 & $28.7 \%$ \\
\hline Any data at age 11 years & 61270 & $22.7 \%$ & 44812 & $22.4 \%$ \\
\hline Any data at age 17 years & 46559 & $17.2 \%$ & 31326 & $15.6 \%$ \\
\hline Race/ethnicity & \multicolumn{2}{|c|}{ Child's race/ethnicity } & \multicolumn{2}{|c|}{ Mother's race/ethnicity } \\
\hline White & 121565 & $45.0 \%$ & 151643 & $75.7 \%$ \\
\hline Black & 23906 & $8.9 \%$ & 23144 & $11.6 \%$ \\
\hline Hispanic & 9018 & $3.3 \%$ & 9123 & $4.6 \%$ \\
\hline Asian & 7941 & $2.9 \%$ & 11421 & $5.7 \%$ \\
\hline Other & 11076 & $4.1 \%$ & 2396 & $1.2 \%$ \\
\hline Missing & 96453 & $35.7 \%$ & 2616 & $1.3 \%$ \\
\hline Insurance & \multicolumn{2}{|c|}{ Medical insurance ${ }^{d}$} & \multicolumn{2}{|c|}{ Delivery payment ${ }^{\mathrm{a}, \mathrm{e}}$} \\
\hline Private & 73412 & $27.2 \%$ & 136022 & $87.5 \%$ \\
\hline Medicaid & 18215 & $6.7 \%$ & 17116 & $11.0 \%$ \\
\hline Other & - & - & 1960 & $1.3 \%$ \\
\hline Missing & 178332 & $66.1 \%$ & 398 & $0.3 \%$ \\
\hline \multicolumn{5}{|l|}{ Mother US born } \\
\hline No & & & 39972 & $20.0 \%$ \\
\hline Yes & & & 158965 & $79.4 \%$ \\
\hline Missing & & & 1406 & $0.7 \%$ \\
\hline \multicolumn{5}{|l|}{$\begin{array}{l}\text { Mother married at time } \\
\text { of birth }\end{array}$} \\
\hline No & & & 31232 & $15.6 \%$ \\
\hline Yes & & & 169026 & $84.4 \%$ \\
\hline Missing & & & 85 & $0.0 \%$ \\
\hline \multicolumn{5}{|l|}{$\begin{array}{l}\text { Mother smoked during } \\
\text { pregnancy }\end{array}$} \\
\hline No & & & 109846 & $93.9 \%$ \\
\hline Yes & & & 6852 & $5.9 \%$ \\
\hline Missing & & & 264 & $0.2 \%$ \\
\hline \multicolumn{5}{|l|}{$\begin{array}{l}\text { Mother had gestational } \\
\text { diabetes mellitus }\end{array}$} \\
\hline No & & & 80953 & $96.1 \%$ \\
\hline Yes & & & 2884 & $3.4 \%$ \\
\hline Missing & & & 413 & $0.5 \%$ \\
\hline \multicolumn{5}{|l|}{ Cesarean delivery $^{a}$} \\
\hline No & & & 118439 & $76.2 \%$ \\
\hline Yes & & & 36256 & $23.3 \%$ \\
\hline Missing & & & 801 & $0.5 \%$ \\
\hline
\end{tabular}

Table 1 Sample socio-demographic characteristics, maternal health behaviors, and childhood obesity and blood pressure outcomes of the singleton children from the existing CENTURY study and Linked CENTURY study (linked with each child's Massachusetts birth certificate), 1980-2008 (Continued)

\begin{tabular}{|c|c|c|c|c|}
\hline \multicolumn{5}{|l|}{ Breastfeeding initiation ${ }^{a}$} \\
\hline No & & & 36097 & $23.2 \%$ \\
\hline Yes & & & 118638 & $76.3 \%$ \\
\hline Missing & & & 761 & $0.5 \%$ \\
\hline $\begin{array}{l}\text { Weight-for-length } \geq 95 \text { th } \\
\text { percentile anytime between } \\
1 \text { and } 24 \text { months [69] }\end{array}$ & 27331 & $22.5 \%$ & 23756 & $22.7 \%$ \\
\hline \multicolumn{5}{|l|}{ BMI $\geq 95$ th percentile [53] } \\
\hline Age 5 years & 8566 & $11.9 \%$ & 6934 & $12.0 \%$ \\
\hline Age 11 years & 9619 & $15.7 \%$ & 7184 & $16.0 \%$ \\
\hline Age 17 years & 5566 & $12.0 \%$ & 3758 & $12.0 \%$ \\
\hline $\begin{array}{l}\text { Systolic blood pressure } \\
\text { z-score [55] }\end{array}$ & $N$ & Mean (SD) & $N$ & Mean (SD) \\
\hline Age 5 years & 66391 & $-0.19(0.81)$ & 52997 & $-0.20(0.81)$ \\
\hline Age 11 years & 57935 & $0.02(0.89)$ & 42391 & $0.02(0.89)$ \\
\hline Age 17 years & 44652 & $-0.11(0.97)$ & 30078 & $-0.11(0.97)$ \\
\hline $\begin{array}{l}\text { Diastolic blood pressure } \\
\text { z-score [55] }\end{array}$ & $N$ & Mean (SD) & N & Mean (SD) \\
\hline Age 5 years & 66391 & $0.08(0.71)$ & 52997 & $0.08(0.71)$ \\
\hline Age 11 years & 57935 & $0.17(0.74)$ & 42391 & $0.17(0.73)$ \\
\hline Age 17 years & 44652 & $0.11(0.75)$ & 30078 & $0.10(0.74)$ \\
\hline
\end{tabular}

${ }^{\mathrm{a} F r o m} 1987$

${ }^{b}$ From 1992

cFrom 1996

${ }^{\mathrm{d}}$ Type of medical insurance at most recent visit recorded in clinical database

${ }^{\mathrm{e}}$ Medical insurance status for the delivery recorded on the birth certificate

\section{Birth certificate measures}

Pregnancy/infant measures The birth certificate contains information on infant's sex, birth weight, plurality, gestational age based on the last menstrual period and clinical estimates, mode of delivery, and parity.

Maternal health behaviors Mothers self-report the average number of cigarettes they smoked daily before and, separately, during pregnancy. The hospital records the mother's total weight gain/loss, whether the mother had GDM, whether the mother had hypertension, whether the mother was breastfeeding at the time the birth certificate was completed (referred to as breastfeeding initiation), and month prenatal care began and the number of prenatal care visits.

Socio-demographic information Mothers and fathers each report their race (white, Black, Asian/Pacific Islander, American Indian, and other), age, place of birth, education, language preference, and marital status (mothers only). 
The birth certificate in Massachusetts also collects information on each parent's ancestry or ethnic heritage (referred to as ethnicity) from 39 items, including several write-in options [56]. The hospital records the mothers' medical insurance status for the delivery.

Geographic information Mothers report the city and zip code of their residential mailing address on the birth certificate and the Registry reports the census tract. We have the ability to link each child's census tract with area-level measures of socioeconomic circumstances through the census and the built environment. Information from commercial databases on locations of parks, fast food restaurants and supermarkets can provide indicators of children's physical activity and food environments.

The birth certificate has undergone multiple revisions since its inception. While a majority of the variables from the birth certificate are available from 1969 onwards, when birth certificate data are first available from MDPH, birth certificates have collected increasingly more information over time. Data for the pregnancy/infant measures as well as maternal race, education, and marital status are available over the entire study period. Data for ethnicity and other socio-demographic characteristics are available primarily from 1987. Similarly, breastfeeding initiation, total weight gain/loss, and pregnancy-related hypertension were included in the birth certificate from 1987. Maternal smoking during pregnancy was collected from 1992 and GDM from 1996.

IRB approval for the Linked CENTURY Study was obtained from Boston College, Harvard Pilgrim Health Care (HPHC), MDPH, and Massachusetts General Hospital. Only approved study personnel at HPHC and MDPH had access to names and dates of birth for data linkage purposes and researchers had access only to a de-identified dataset.

\section{Linkage procedure}

In collaboration with $\mathrm{MDPH}$, we developed a process for transferring the data between institutions (Fig. 1) and linking the datasets (Table 2). The Research Support Data Center at HPHC created a dataset that contained a random ID for each CENTURY Study child, child's name and date of birth, mother's date of birth, and all study variables. The Research Support Data Center sent the dataset to MDPH who linked each child with their birth certificate based on a linkage algorithm comparing the child's name and date of birth and the mother's date of birth. Table 2 presents the matching phase linkage algorithm and resulting number of matches for the six permutations of the algorithm. The majority of matches occurred only using the child information: $45.2 \%$ of matches were based on the child's first and last name and date of birth, while a further $33.3 \%$ of matches were

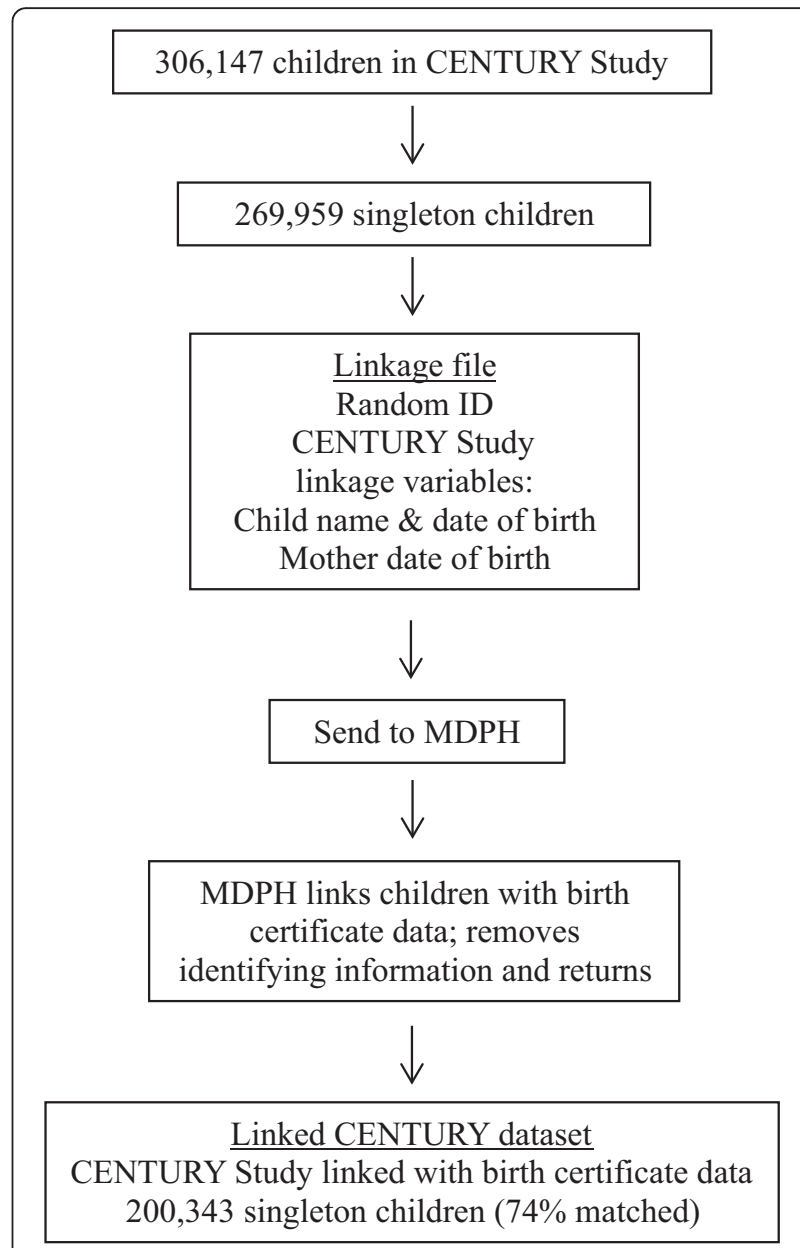

Fig. 1 Flow diagram for linking the CENTURY Study data with each child's Massachusetts birth certificate

Table 2 Success rate of linkage algorithm by type of match $(N=200,343)$

\begin{tabular}{|c|c|c|c|}
\hline Matching phase & Type of match & $\begin{array}{l}\text { Number } \\
\text { linked }\end{array}$ & $\%$ \\
\hline 1 & $\begin{array}{l}\text { Child's first, middle, and last name } \\
\& \text { dob and mother's dob }\end{array}$ & 5282 & $2.6 \%$ \\
\hline 2 & $\begin{array}{l}\text { Child's first, middle initial, and last } \\
\text { name \& dob and mother's dob }\end{array}$ & 32094 & $16.0 \%$ \\
\hline 3 & $\begin{array}{l}\text { Child's first, middle, and last name } \\
\& \text { dob }\end{array}$ & 3035 & $1.5 \%$ \\
\hline 4 & $\begin{array}{l}\text { Child's first, middle initial, and last } \\
\text { name \& dob }\end{array}$ & 66730 & $33.3 \%$ \\
\hline 5 & Child's first and last name \& dob & 90506 & $45.2 \%$ \\
\hline 6 & $\begin{array}{l}\text { Child's first } 3 \text { letters of first name } \\
\text { and last name \& dob }\end{array}$ & 2696 & $1.3 \%$ \\
\hline
\end{tabular}


based on the child's first, middle initial, and last name and date of birth. MDPH then removed identifying information and returned the dataset to our study team.

\section{Results}

Overall, $74.2 \%$ of the 269,959 singleton children were matched, resulting in 200,343 children in the Linked CENTURY Study with 1,580,597 well child visits. On average, each child had 7.9 visits (SD 6.6), range 1-93. The proportion of children who were linked to their birth certificate was higher in recent years from $47.8 \%$ in 1969 to $92.4 \%$ in 2008 (Fig. 2). As a result, $77.6 \%$ of the children in the dataset were born from 1987 onwards. Differences in the proportion of children linked may be a result of when changes in the birth certificate were introduced (i.e., new items were added in 1987) (personal communication with Kevin Foster, October 14, 2014). Within this cohort, $60.9 \%(121,917)$ children have at least one other sibling in the dataset.

Sample socio-demographic characteristics, maternal health behaviors, and childhood obesity and blood pressure outcomes of Linked CENTURY Study children are shown in Table 1. Approximately half of the sample had height/weight data available between 1 and $<24.0$ months, one-third at age 5 , and one-fifth at age 11 years. There is a $91 \%$ agreement between maternal race/ethnicity from the birth certificate and children's race/ethnicity from the existing CENTURY Study. Using maternal race/ethnicity as an indicator of children's race/ethnicity, $75.7 \%$ of children were white, $11.6 \%$ black, $4.6 \%$ Hispanic, $5.7 \%$ Asian, and only $1.3 \%$ had missing data. Using medical insurance status from the birth certificate as an indicator of socioeconomic circumstances, $11.0 \%$ of mothers had their delivery paid for by public health insurance and $0.3 \%$ had missing information.

Based on socio-demographic information from the birth certificate, $20.0 \%$ of mothers were non-US born, $15.6 \%$ were not married at the time of birth, $5.9 \%$ smoked during pregnancy and $76.3 \%$ initiated breastfeeding. Using clinical data from the CENTURY Study, $22.7 \%$ of children had a weight-for-length $\geq 95^{\text {th }}$ percentile between 1 and 24 months and $12.0 \%$ had a $\mathrm{BMI} \geq 95^{\text {th }}$ percentile at ages 5 and 17 years.

Using clinical data from the CENTURY Study, $92 \%$ of children with a visit at age 5 years had blood pressure measurement, $95 \%$ at 11 years and $96 \%$ at 17 years. At ages 5,11 , and 17 years, mean (SD) systolic blood pressure $\mathrm{mm} \mathrm{Hg}$ values were 93.0 (8.7), 105.8 (9.8), and 114.5 (10.6) and mean (SD) diastolic blood pressure mm Hg values were 55.8 (8.0), 64.2 (8.3) and 68.9 (8.3). Blood pressure z-scores are provided in Table 1.

We compared children who were successfully linked with their birth certificate and those who were not linked (Table 3). Overall, differences by sex were minimal. Children not linked were more likely to be born in the 1970s and 1980s, from an ethnic minority group, or have missing race/ethnicity or medical insurance information.

A feature of the Linked CENTURY Study is that $94.0 \%$ $(188,334)$ of children have some father information available. Table 4 compares the socio-demographic information from the birth certificate between mothers and fathers. Fathers were slightly older at the time of birth (mean 32 versus 30 years) and more likely to have $16+$ years of education than mothers (18.2 \% versus $14.0 \%)$; however, there were few differences by race/ethnicity or nativity.

Although the Linked CENTURY Study included children from eastern Massachusetts only, we compared selected

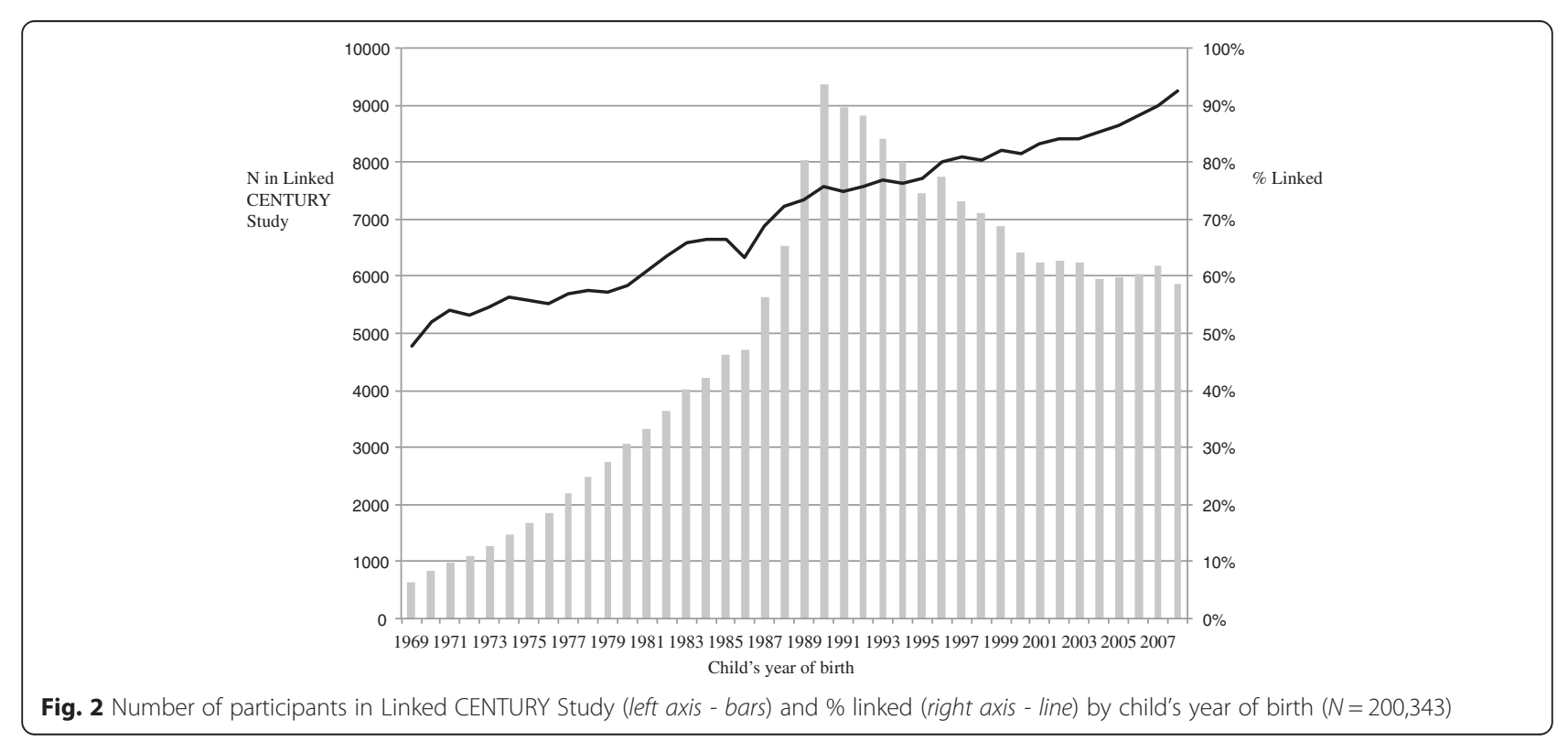


Table 3 Socio-demographic characteristics from the CENTURY Study of children included in the Linked CENTURY Study and those who were not linked

\begin{tabular}{|c|c|c|}
\hline & $\begin{array}{l}\text { Linked CENTURY Study } \\
(N=200343)\end{array}$ & $\begin{array}{l}\text { Not linked } \\
(N=69616)\end{array}$ \\
\hline Characteristics & $\%$ & $\%$ \\
\hline \multicolumn{3}{|c|}{ Child's year of birth (decade) } \\
\hline 1970s & 8.6 & 19.8 \\
\hline $1980 \mathrm{~s}$ & 23.9 & 34.0 \\
\hline $1990 s$ & 40.0 & 33.2 \\
\hline $2000 s$ & 27.6 & 13.0 \\
\hline \multicolumn{3}{|l|}{ Child's sex } \\
\hline Male & 50.3 & 51.0 \\
\hline Female & 49.7 & 49.1 \\
\hline \multicolumn{3}{|c|}{ Child's race/ethnicity } \\
\hline White & 49.1 & 33.3 \\
\hline Black & 7.7 & 12.1 \\
\hline Hispanic & 2.7 & 5.3 \\
\hline Asian & 2.7 & 3.8 \\
\hline Other & 3.5 & 5.8 \\
\hline Missing & 34.3 & 39.8 \\
\hline \multicolumn{3}{|c|}{ Medical insurance ${ }^{a}$} \\
\hline Private & 29.5 & 20.6 \\
\hline Medicaid & 6.8 & 6.5 \\
\hline Missing & 63.7 & 72.9 \\
\hline
\end{tabular}

Table 4 Maternal and paternal socio-demographic information from the birth certificate

\begin{tabular}{|c|c|c|c|c|}
\hline \multirow[b]{2}{*}{ Characteristic } & \multicolumn{2}{|c|}{ Maternal $(N=200,343)$} & \multicolumn{2}{|c|}{ Paternal $(N=188,334)$} \\
\hline & $N$ & Mean (SD) or \% & $N$ & Mean (SD) or \% \\
\hline Age, years & 199986 & $30(6)$ & 175425 & $32(6)$ \\
\hline \multicolumn{5}{|l|}{ Race/ethnicity } \\
\hline White & 151643 & $76.7 \%$ & 146572 & $79.0 \%$ \\
\hline Black & 23144 & $11.7 \%$ & 18487 & $10.0 \%$ \\
\hline Hispanic & 9123 & $4.6 \%$ & 7992 & $4.3 \%$ \\
\hline Asian & 11421 & $5.8 \%$ & 10105 & $5.5 \%$ \\
\hline Other & 2396 & $1.2 \%$ & 2334 & $1.3 \%$ \\
\hline \multicolumn{5}{|l|}{ Education } \\
\hline$<12$ years & 2433 & $1.2 \%$ & 2070 & $1.1 \%$ \\
\hline 12 years & 67141 & $34.0 \%$ & 64515 & $35.1 \%$ \\
\hline $13-15$ years & 100254 & $50.8 \%$ & 83868 & $45.6 \%$ \\
\hline $16+$ years & 27672 & $14.0 \%$ & 33489 & $18.2 \%$ \\
\hline \multicolumn{5}{|l|}{ US born } \\
\hline No & 39972 & $20.1 \%$ & 39671 & $21.5 \%$ \\
\hline Yes & 158965 & $79.9 \%$ & 144668 & $78.5 \%$ \\
\hline
\end{tabular}

maternal socio-demographic characteristics between singleton children born from 2004 to 2008 and all Massachusetts births in 2008 [57] (Table 5). Both datasets had similar proportions of mothers who were Black, US born, had GDM, and a cesarean delivery. The Linked CENTURY Study had more white $(73.2 \%)$ and Asian mothers (11.4\%) and fewer Hispanic mothers (4.9 \%) than all Massachusetts births (67.2 \%, $7.7 \%$, $14.2 \%$, respectively). While the Linked CENTURY Study had fewer mothers not married at the time of birth (17.7\% versus $24.0 \%)$, mothers were more likely to have initiated breastfeeding (86.6\% versus $80.8 \%$ ) than all Massachusetts births.

\section{Discussion}

By linking routinely-collected data sources, we can address research questions that could not be answered with either source alone. Linkage of the existing CENTURY Study, a clinical database, with each child's birth certificate, a public health data source, has created a dataset with the potential to examine the etiology of racial/ethnic and socioeconomic disparities in childhood obesity. The Linked CENTURY Study is a cohort of 200,343 children who can be followed through age 18 years. Future data extractions can update the dataset with newer cohorts of children as well as extend the longitudinal nature of the dataset for the existing children from 2008 through present.

There are many advantages to the type of data linkage we report. Harvesting data from electronic health records allowed us to generate a large, diverse cohort of children, which has the potential to be updated with more recent height and weight data or other items through future data extractions. Linking databases is a cost-effective study design for examining research questions using a life course perspective. Although the process of working with MDPH and HVMA was time consuming for the study team and personnel time should not be under-estimated, the physical cost of linking the data sources was less than $\$ 1,000$. This price is substantially less than the cost of developing a cohort with primary data collection and long-term follow up. Linking databases has enabled us to fill in information that was missing in one source, but not the other. We can also conduct validation studies of an item from one source when the other can serve as a gold standard. In addition, most research on childhood obesity focuses on maternal or household indicators of socioeconomic status [1]. However, through the birth certificate data, we have the ability to look at the influence of both parents. The Linked CENTURY Study has socio-demographic information on the fathers of almost 190,000 children. Finally, little is known about the role of the neighborhood in explaining disparities in childhood obesity because 
Table 5 Comparison of selected maternal socio-demographic characteristics and health behaviors in the singleton children from the Linked CENTURY Study, births from 2004 to 2008, and all Massachusetts births in 2008 [57]

\begin{tabular}{|c|c|c|c|c|}
\hline \multirow[b]{3}{*}{ Maternal characteristics } & \multicolumn{2}{|c|}{ Linked CENTURY Study } & \multicolumn{2}{|c|}{ Massachusetts births } \\
\hline & \multicolumn{2}{|c|}{ 2004-2008 $(N=30,016)$} & \multicolumn{2}{|c|}{$2008(N=76,969)$} \\
\hline & Total $N$ & $\%$ & Total N & $\%$ \\
\hline \multicolumn{5}{|l|}{ Race/ethnicity } \\
\hline White & 21947 & 73.2 & 51,760 & 67.2 \\
\hline Black & 2610 & 8.7 & 6,652 & 8.6 \\
\hline Hispanic & 1471 & 4.9 & 10,895 & 14.2 \\
\hline Asian & 3413 & 11.4 & 5,958 & 7.7 \\
\hline Other & 544 & 1.8 & - & - \\
\hline Not US born & 7935 & 26.4 & 21,299 & 27.7 \\
\hline Not married at time of birth & 5323 & 17.7 & 26,146 & 34.0 \\
\hline Had gestational diabetes mellitus & 1240 & 4.1 & 3,086 & 4.0 \\
\hline Cesarean delivery & 9700 & 32.4 & 26,240 & 34.3 \\
\hline Initiated breastfeeding & 25959 & 86.6 & 61,033 & 80.8 \\
\hline
\end{tabular}

geographical data are often not collected or available. Census tract information from the birth certificate will allow us to link to additional sources and examine the role of both area-level socioeconomic indicators and measures of the built environment on childhood obesity. While geographic information is currently only available from the child's place of birth, the study team is exploring data extraction of the current residential address.

Most epidemiological studies examining risk factors for childhood obesity have been observational and, consequently, evidence has been based on associations. There are nearly 122,000 siblings in the Linked CENTURY. Sibling pair methodologies will allow us to reduce confounding by better controlling for genetic and shared environmental and familial factors [32]. Currently, only a limited number of sibling pair studies have examined early life risk factors, including smoking during pregnancy [35, 36], GDM [40, 44], gestational weight gain [41, 42], and breastfeeding [34, 37-39, 43]. We are not aware of sibling pair studies on accelerated infant weight gain and none of the more recent risk factors such as cesarean delivery or antibiotic use. With geographical data, it is also possible to explore differences in neighborhood effects between siblings who moved residence throughout childhood. Alternative methodologies to observational studies will produce less biased estimates and, ultimately, insights into areas for prevention. The study team has presented on several analyses using siblings in the Linked CENTURY Study to compare childhood obesity outcomes within families [58-60].

There are also a number of limitations that should be addressed. Linking datasets across institutions can be very time-intensive. In addition to the time that is required to apply for IRB approval from each institution, data confidentiality agreements and developing linkage algorithms can take many years. In addition, some institutions may have never been in contact previously and it can take time to develop these relationships.

Since some routinely-collected data are not objectively measured, there may be potential misclassification. Child race/ethnicity in the CENTURY Study was collected by either the parent or clinician, but it is not possible to determine who reported it. Some of the health-related items on the birth certificate are reported by the parent(s) or a hospital representative. For example, a mother reports on the average number of cigarettes she smoked during pregnancy on an average day. Maternal smoking during pregnancy is under-reported on the birth certificate compared to information on smoking collected on confidential surveys completed postpartum [61]. A hospital representative records yes or no in response to 'is mother breastfeeding', which serves as an indicator of breastfeeding initiation. In this case, a study in Massachusetts demonstrated a high level of agreement between the birth certificate and hospital infant feeding records [62]. The item of maternal total weight gained/lost is reported by the hospital at the time of delivery, but not necessarily based on measured weight and information on pre-pregnancy weight is not recorded. Validation studies have found misreporting of weight gain among women with a high body mass index or at the extremes of gestational weight gain [63, 64], posing some challenges for examining gestational weight gain using birth certificate data.

Attrition and selection bias in linked datasets are threats to internal validity similar to those in prospective cohort studies. There are two sources of missing data in our study. First, if children leave the clinical practice, then they will no longer be in our dataset. Second, some 
children have simply not aged into a category, i.e., children born after 1997 had not yet reached age 11. While $28.7 \%$ of children have data at 5 years, only $22.4 \%$ of children have data at 11 years. Extracting data from children's electronic health records from 2009 onwards will increase the sample size at these later ages. A further limitation of clinical databases is that they often underrepresent diverse populations who have less access to clinical care. HVMA accepted children with Medicaid insurance from 1987 onwards, suggesting that the database is less likely to be representative in prior years. However, using recent data, many of the maternal characteristics in the Linked CENTURY Study are similar to those for all births in Massachusetts (Table 5). Although the Linked CENTURY Study includes more mothers who were white and married at the time of birth, data specific to Eastern Massachusetts are not available.

Increasing the use of electronic health records to improve the coordination of care is an important feature of the Patient Protection and Affordable Care Act [65]. Internationally, data linkage is an active component of evaluating health system performance [66] and, ultimately, improving care and population health. Learning from new data linkage projects in the US [67-69] and more established ones in Europe [70-72] will provide further evidence on the potential for data linkages with electronic health records to address important public health problems like childhood obesity.

\section{Conclusions}

Childhood obesity is prevalent, of consequence, has its origins in the earliest stages of life, and disproportionately affects children from racial/ethnic minority groups and from disadvantaged backgrounds. The Linked CENTURY Study, created by incorporating clinical data with birth certificates, is a unique dataset with nearly complete racial/ethnic and socio-demographic information from both parents. Thus, the Linked CENTURY Study has the potential to examine the etiology of racial/ethnic and socioeconomic disparities in childhood obesity.

\section{Abbreviations}

BMI: Body mass index; CDC: Centers for Disease Control and Prevention; dob: date of birth; GDM: Gestational diabetes mellitus; HPHC: Harvard Pilgrim Health Care; HVMA: Harvard Vanguard Medical Associates;

MDPH: Massachusetts Department of Public Health; WFL: Weight-for-length.

\section{Competing interests}

The authors declare that they have no competing interests.

\section{Authors' contributions}

SSH conceived of the data linkage, participated in the study design, coordinated the data linkage, and drafted the manuscript. SLR-S performed the statistical analysis. KPK consulted on the statistical analysis. MWG created the original CENTURY Study and participated in the study design. MM consulted on the clinical aspects of the study. EMT created the original CENTURY Study and participated in the study design. All authors read and approved the final manuscript.

\section{Acknowledgements}

This work was partially funded by grants from the NIH (R00 HD068506) to Dr. Hawkins and the National Center for Chronic Disease Prevention and Health Promotion (Contract No. 200-2008-M-26882) to Dr. Taveras. The content is solely the responsibility of the authors and does not necessarily represent the official views of the funders.

\section{Author details}

'Boston College, School of Social Work, McGuinn Hall, 140 Commonwealth Avenue, Chestnut Hill, MA, USA. ${ }^{2}$ Obesity Prevention Program, Department of Population Medicine, Harvard Medical School and Harvard Pilgrim Health Care Institute, Boston, MA, USA. ${ }^{3}$ Penn Center for Health Care Innovation, Philadelphia, PA, USA. ${ }^{4}$ Division of General Academic Pediatrics, Department of Pediatrics, Massachusetts General Hospital for Children, Boston, MA, USA. ${ }^{5}$ Department of Nutrition, Harvard T.H. Chan School of Public Health, Boston, MA, USA.

Received: 17 July 2015 Accepted: 29 February 2016

Published online: 09 March 2016

\section{References}

1. Ogden $\mathrm{CL}$, Carroll MD, Kit BK, Flegal KM. Prevalence of childhood and adult obesity in the United States, 2011-2012. JAMA. 2014;311(8):806-14.

2. Centers for Disease Control and Prevention. Vital signs: obesity among lowincome, preschool-aged children-United States, 2008-2011. MMWR Morb Mortal Wkly Rep. 2013;62(31):629-34.

3. Ben-Shlomo Y, Kuh D. A life course approach to chronic disease epidemiology: conceptual models, empirical challenges and interdisciplinary perspectives. Int J Epidemiol. 2002;31(2):285-93.

4. Hawkins SS, Oken E, Gillman MW. Early in the life course: time for obesity prevention. In: Halfon N, Forrest C, Lerner R, Faustman EM, editors. Handbook of life course health development science. New York: Springer; 2015.

5. Oken E, Levitan EB, Gillman MW. Maternal smoking during pregnancy and child overweight: systematic review and meta-analysis. Int J Obes. 2008; 32(2):201-10.

6. Weng SF, Redsell SA, Swift JA, Yang M, Glazebrook CP. Systematic review and meta-analyses of risk factors for childhood overweight identifiable during infancy. Arch Dis Child. 2012;97(12):1019-26.

7. Ino T. A meta-analysis of association between maternal smoking during pregnancy and offspring obesity. Pediatr Int. 2010;52(1):94-9.

8. Lau EY, Liu J, Archer E, McDonald SM, Liu J. Maternal weight gain in pregnancy and risk of obesity among offspring: a systematic review. J Obes. 2014;2014:524939.

9. Mamun AA, Mannan M, Doi SA. Gestational weight gain in relation to offspring obesity over the life course: a systematic review and bias-adjusted meta-analysis. Obes Rev. 2014;15(4):338-47.

10. Nehring I, Lehmann S, von Kries R. Gestational weight gain in accordance to the IOM/NRC criteria and the risk for childhood overweight: a meta-analysis. Pediatr Obes. 2013;8(3):218-24.

11. Kim SY, England JL, Sharma JA, Njoroge T. Gestational diabetes mellitus and risk of childhood overweight and obesity in offspring: a systematic review. Exp Diabetes Res. 2011;2011:541308.

12. Monteiro PO, Victora CG. Rapid growth in infancy and childhood and obesity in later life-a systematic review. Obes Rev. 2005;6(2):143-54.

13. Baird J, Fisher D, Lucas P, Kleijnen J, Roberts H, Law C. Being big or growing fast: systematic review of size and growth in infancy and later obesity. BMJ. 2005;331(7522):929.

14. Arenz S, Ruckerl R, Koletzko B, von Kries R. Breast-feeding and childhood obesity-a systematic review. Int J Obes Relat Metab Disord. 2004:28(10):1247-56

15. Harder T, Bergmann R, Kallischnigg G, Plagemann A. Duration of breastfeeding and risk of overweight: a meta-analysis. Am J Epidemiol. 2005; 162(5):397-403.

16. Owen CG, Martin RM, Whincup PH, Smith GD, Cook DG. Effect of infant feeding on the risk of obesity across the life course: a quantitative review of published evidence. Pediatrics. 2005;115(5):1367-77.

17. Yan J, Liu L, Zhu Y, Huang G, Wang PP. The association between breastfeeding and childhood obesity: a meta-analysis. BMC Public Health. 2014;14:1267.

18. Li HT, Zhou YB, Liu JM. The impact of cesarean section on offspring overweight and obesity: a systematic review and meta-analysis. Int J Obes. 2013;37(7):893-9. 
19. Darmasseelane K, Hyde MJ, Santhakumaran S, Gale C, Modi N. Mode of delivery and offspring body mass index, overweight and obesity in adult life: a systematic review and meta-analysis. PLoS One. 2014;9(2): e87896.

20. Bailey LC, Forrest CB, Zhang P, Richards TM, Livshits A, DeRusso PA. Association of antibiotics in infancy with early childhood obesity. JAMA Pediatr. 2014;168(11):1063-9.

21. Saari A, Virta LJ, Sankilampi U, Dunkel L, Saxen H. Antibiotic exposure in infancy and risk of being overweight in the first 24 months of life. Pediatrics. 2015;135(4):617-26.

22. Grow HM, Cook AJ, Arterburn DE, Saelens BE, Drewnowski A, Lozano P. Child obesity associated with social disadvantage of children's neighborhoods. Soc Sci Med. 2010:71(3):584-91.

23. Fiechtner L, Block J, Duncan DT, Gillman MW, Gortmaker SL, Melly SJ, et al. Proximity to supermarkets associated with higher body mass index among overweight and obese preschool-age children. Prev Med. 2013;56(3-4):218-21.

24. Lovasi GS, Schwartz-Soicher O, Quinn JW, Berger DK, Neckerman KM, Jaslow $\mathrm{R}$, et al. Neighborhood safety and green space as predictors of obesity among preschool children from low-income families in New York City. Prev Med. 2013;57(3):189-93.

25. Carroll-Scott A, Gilstad-Hayden K, Rosenthal L, Peters SM, McCaslin C, Joyce $R$, et al. Disentangling neighborhood contextual associations with child body mass index, diet, and physical activity: the role of built, socioeconomic, and social environments. Soc Sci Med. 2013;95:106-14.

26. Papas MA, Alberg AJ, Ewing R, Helzlsouer KJ, Gary TL, Klassen AC. The built environment and obesity. Epidemiol Rev. 2007;29:129-43.

27. Dunton GF, Kaplan J, Wolch J, Jerrett M, Reynolds KD. Physical environmental correlates of childhood obesity: a systematic review. Obes Rev. 2009;10(4):393-402.

28. Lovasi GS, Hutson MA, Guerra M, Neckerman KM. Built environments and obesity in disadvantaged populations. Epidemiol Rev. 2009;31:7-20.

29. Rossen LM. Neighbourhood economic deprivation explains racial/ethnic disparities in overweight and obesity among children and adolescents in the USA. J Epidemiol Community Health. 2014;68(2):123-9.

30. Powell LM, Wada R, Krauss RC, Wang Y. Ethnic disparities in adolescent body mass index in the United States: the role of parental socioeconomic status and economic contextual factors. Soc Sci Med. 2012;75(3):469-76.

31. Kimbro RT, Denney JT. Neighborhood context and racial/ethnic differences in young children's obesity: structural barriers to interventions. Soc Sci Med. 2013:95:97-105.

32. Brion MJ. Commentary: Assessing the impact of breastfeeding on child health: where conventional methods alone fall short for reliably establishing causal inference. Int J Epidemiol. 2010;39(1):306-7.

33. Knopik VS. Commentary: Smoking during pregnancy-genes and environment weigh in. Int J Epidemiol. 2010;39(5):1203-5.

34. Gillman MW, Rifas-Shiman SL, Berkey CS, Frazier AL, Rockett HR, Camargo Jr CA, et al. Breast-feeding and overweight in adolescence: within-family analysis [corrected]. Epidemiology. 2006;17(1):112-4.

35. Iliadou AN, Koupil I, Villamor E, Altman D, Hultman C, Langstrom N, et al. Familial factors confound the association between maternal smoking during pregnancy and young adult offspring overweight. Int J Epidemiol. 2010; 39(5):1193-202.

36. Gilman SE, Gardener H, Buka SL. Maternal smoking during pregnancy and children's cognitive and physical development: a causal risk factor? Am J Epidemiol. 2008;168(5):522-31.

37. Metzger MW, McDade TW. Breastfeeding as obesity prevention in the United States: a sibling difference model. Am J Hum Biol. 2010;22(3): 291-6.

38. OTierney PF, Barker DJ, Osmond C, Kajantie E, Eriksson JG. Duration of breast-feeding and adiposity in adult life. J Nutr. 2009;139(2):422S-5S.

39. Nelson MC, Gordon-Larsen P, Adair LS. Are adolescents who were breast-fed less likely to be overweight? Analyses of sibling pairs to reduce confounding. Epidemiology. 2005;16(2):247-53.

40. Lawlor DA, Lichtenstein P, Langstrom N. Association of maternal diabetes mellitus in pregnancy with offspring adiposity into early adulthood: sibling study in a prospective cohort of 280,866 men from 248,293 families. Circulation. 2011;123(3):258-65.

41. Lawlor DA, Lichtenstein P, Fraser A, Langstrom N. Does maternal weight gain in pregnancy have long-term effects on offspring adiposity? A sibling study in a prospective cohort of 146,894 men from 136,050 families. Am J Clin Nutr. 2011;94(1):142-8.
42. Branum AM, Parker JD, Keim SA, Schempf AH. Prepregnancy body mass index and gestational weight gain in relation to child body mass index among siblings. Am J Epidemiol. 2011;174(10):1159-65.

43. Colen CG, Ramey DM. Is breast truly best? Estimating the effects of breastfeeding on long-term child health and wellbeing in the United States using sibling comparisons. Soc Sci Med. 2014;109:55-65.

44. Dabelea D, Hanson RL, Lindsay RS, Pettitt DJ, Imperatore G, Gabir MM, et al. Intrauterine exposure to diabetes conveys risks for type 2 diabetes and obesity: a study of discordant sibships. Diabetes. 2000;49(12):2208-11.

45. Fraser A, Macdonald-Wallis C, Tilling K, Boyd A, Golding J, Davey Smith G, et al. Cohort Profile: the Avon Longitudinal Study of Parents and Children: ALSPAC mothers cohort. Int J Epidemiol. 2013;42(1):97-110.

46. Oken E, Baccarelli AA, Gold DR, Kleinman KP, Litonjua AA, De Meo D, et al Cohort profile: project viva. Int J Epidemiol. 2015;44(1):37-48.

47. Wen X, Kleinman K, Gillman MW, Rifas-Shiman SL, Taveras EM. Childhood body mass index trajectories: modeling, characterizing, pairwise correlations and socio-demographic predictors of trajectory characteristics. BMC Med Res Methodol. 2012;12:38.

48. Kim J, Peterson KE, Scanlon KS, Fitzmaurice GM, Must A, Oken E, et al. Trends in overweight from 1980 through 2001 among preschool-aged children enrolled in a health maintenance organization. Obesity. 2006;14(7):1107-12.

49. Taveras EM, Rifas-Shiman SL, Sherry B, Oken E, Haines J, Kleinman K, et al. Crossing growth percentiles in infancy and risk of obesity in childhood. Arch Pediatr Adolesc Med. 2011;165(11):993-8.

50. Hazlehurst B, Sittig DF, Stevens VJ, Smith KS, Hollis JF, Vogt TM, et al. Natural language processing in the electronic medical record: assessing clinician adherence to tobacco treatment guidelines. Am J Prev Med. 2005;29(5):434-9.

51. Friedman C, Shagina L, Lussier $Y$, Hripcsak G. Automated encoding of clinical documents based on natural language processing. J Am Med Inform Assoc. 2004;11(5):392-402.

52. Rifas-Shiman SL, Rich-Edwards JW, Scanlon KS, Kleinman KP, Gillman MW. Misdiagnosis of overweight and underweight children younger than 2 years of age due to length measurement bias. Med Gen Med. 2005;7(4):56.

53. Kuczmarski RJ, Ogden CL, Guo SS, Grummer-Strawn LM, Flegal KM, Mei Z, et al. 2000 CDC Growth Charts for the United States: methods and development. Vital Health Stat 11. 2002:(246):1-190

54. Pickering TG, Hall JE, Appel LJ, Falkner BE, Graves J, Hill MN, et al. Recommendations for blood pressure measurement in humans and experimental animals: Part 1: blood pressure measurement in humans: a statement for professionals from the Subcommittee of Professional and Public Education of the American Heart Association Council on High Blood Pressure Research. Hypertension. 2005;45(1):142-61.

55. National High Blood Pressure Education Program Working Group on High Blood Pressure in Children and Adolescents. The fourth report on the diagnosis, evaluation, and treatment of high blood pressure in children and adolescents. Pediatrics. 2004;114(2 Suppl 4th Report):555-76.

56. Hawkins SS, Torres B, May GS, Cohen BB. Setting the standards for collecting ethnicity data in the Commonwealth of Massachusetts. J Public Health Manag Pract. 2011;17(6):550-3.

57. Massachusetts Department of Public Health. Massachusetts Births 2008. Boston: Massachusetts Department of Public Health; 2010.

58. Rifas-Shiman SL, Hawkins SS, Kleinman K, Gillman MW, Taveras EM. Delivery by caesarean section and BMl-z at age 5 years: within-family analysis. Los Angeles: The Obesity Society; 2015.

59. Hawkins SS, Rifas-Shiman SL, Baum CF, Gillman MW, Taveras EM. Using a sibling design to examine the association of breastfeeding with early childhood obesity. Miami: Epidemiology Congress of the Americas; 2016.

60. Rifas-Shiman S, Hawkins SS, Gillman MW, Taveras EM. Smoking during pregnancy and BMI-z at age 5 years: within-family analysis. Miami: Epidemiology Congress of the Americas; 2016.

61. Allen AM, Dietz PM, Tong VT, England L, Prince CB. Prenatal smoking prevalence ascertained from two population-based data sources: birth certificates and PRAMS questionnaires, 2004. Public Health Rep. 2008;123(5):586-92.

62. Navidi T, Chaudhuri J, Merewood A. Accuracy of breastfeeding data on the Massachusetts birth certificate. J Hum Lact. 2009;25(2):151-6.

63. Bodnar LM, Abrams B, Bertolet M, Gernand AD, Parisi SM, Himes KP, et al. Validity of birth certificate-derived maternal weight data. Paediatr Perinat Epidemiol. 2014;28(3):203-12.

64. Wright CS, Weiner M, Localio R, Song L, Chen P, Rubin D. Misreport of gestational weight gain (GWG) in birth certificate data. Matern Child Health J. 2012;16(1):197-202. 
65. U.S. Department of Health \& Human Services. Key features of the Affordable Care Act by year. http://www.hhs.gov/healthcare/facts/timeline/timelinetext.html. Accessed 6 March 2015.

66. EuroReach Health Data Navigator: Data linkage. http://www.healthdatanavigator. eu/data-management/data-linkage. Accessed 6 March 2015.

67. Hillier TA, Pedula KL, Schmidt MM, Mullen JA, Charles MA, Pettitt DJ. Childhood obesity and metabolic imprinting: the ongoing effects of maternal hyperglycemia. Diabetes Care. 2007;30(9):2287-92.

68. Angier H, Gold R, Crawford C, P O'Malley J, J Tillotson C, Marino M, et al. Linkage methods for connecting children with parents in electronic health record and state public health insurance data. Matern Child Health J. 2014; 18(9):2025-33.

69. Heerman WJ, Bian A, Shintani A, Barkin SL. Interaction between maternal prepregnancy body mass index and gestational weight gain shapes infant growth. Acad Pediatr. 2014;14(5):463-70.

70. OECD. Strengthening health information infrastructure for health care quality governance: Good practices, new opportunities and data privacy protection challenges. Paris: OECD Health Policy Studies, OECD Publishing; 2013.

71. Baker JL, Sorensen TI. Obesity research based on the Copenhagen School Health Records Register. Scand J Public Health. 2011;39(7 Suppl):196-200.

72. Olsen SF, Birgisdottir BE, Halldorsson TI, Brantsaeter AL, Haugen M, Torjusen $\mathrm{H}$, et al. Possibilities and considerations when merging dietary data from the world's two largest pregnancy cohorts: the Danish National Birth Cohort and the Norwegian Mother and Child Cohort Study. Acta Obstet Gynecol Scand. 2014;93(11):1131-40.

\section{Submit your next manuscript to BioMed Central and we will help you at every step:}

- We accept pre-submission inquiries

- Our selector tool helps you to find the most relevant journal

- We provide round the clock customer support

- Convenient online submission

- Thorough peer review

- Inclusion in PubMed and all major indexing services

- Maximum visibility for your research

Submit your manuscript at www.biomedcentral.com/submit

C Biomed Central 